\title{
Methylphenidate effects on prefrontal functioning during attentional-capture and response inhibition
}

Citation for published version (APA):

Pauls, A. M., O'Daly, O. G., Rubia, K., Riedel, W. J., Williams, S. C., \& Mehta, M. A. (2012).

Methylphenidate effects on prefrontal functioning during attentional-capture and response inhibition. Biological Psychiatry, 72(2), 142-149. https://doi.org/10.1016/j.biopsych.2012.03.028

Document status and date:

Published: 01/01/2012

DOI:

10.1016/j.biopsych.2012.03.028

Document Version:

Publisher's PDF, also known as Version of record

Document license:

Taverne

Please check the document version of this publication:

- A submitted manuscript is the version of the article upon submission and before peer-review. There can be important differences between the submitted version and the official published version of record.

People interested in the research are advised to contact the author for the final version of the publication, or visit the DOI to the publisher's website.

- The final author version and the galley proof are versions of the publication after peer review.

- The final published version features the final layout of the paper including the volume, issue and page numbers.

Link to publication

\footnotetext{
General rights rights.

- You may freely distribute the URL identifying the publication in the public portal. please follow below link for the End User Agreement:

www.umlib.nl/taverne-license

Take down policy

If you believe that this document breaches copyright please contact us at:

repository@maastrichtuniversity.nl

providing details and we will investigate your claim.
}

Copyright and moral rights for the publications made accessible in the public portal are retained by the authors and/or other copyright owners and it is a condition of accessing publications that users recognise and abide by the legal requirements associated with these

- Users may download and print one copy of any publication from the public portal for the purpose of private study or research.

- You may not further distribute the material or use it for any profit-making activity or commercial gain

If the publication is distributed under the terms of Article $25 \mathrm{fa}$ of the Dutch Copyright Act, indicated by the "Taverne" license above, 


\title{
Methylphenidate Effects on Prefrontal Functioning During Attentional-Capture and Response Inhibition
}

\begin{abstract}
Astrid M. Pauls, Owen G. O’Daly, Katya Rubia, Wim J. Riedel, Steven C.R. Williams, and Mitul A. Mehta
Background: Methylphenidate improves motor response inhibition, typically assessed with the stop-signal task. The exact underlying mechanism for this, however, remains unknown. In addition, recent studies highlight that stop signals can have a confounding attentionalcapture effect because of their low frequency in the task. In the current study, we assessed the effects of methylphenidate on neural networks of inhibitory control and attentional-capture within the context of two inhibitory control tasks.
\end{abstract}

Methods: The effects of methylphenidate $(40 \mathrm{mg}$ ) were assessed using functional magnetic resonance imaging in 16 healthy volunteers in a within-subject, double-blind, placebo-controlled design.

Results: Methylphenidate significantly reduced activation of different regions within the right inferior frontal gyrus/insula to infrequent stimuli associated with successful inhibition, failed inhibition, and attentional capture. These inferior frontal gyrus regions showed different interregional connections with inhibitory and attention networks. For failed inhibitions, methylphenidate increased activation within performance-monitoring regions, including the superior frontal, anterior cingulate, and parietal-occipital cortices, but only after controlling for attentional capture.

Conclusions: Our findings suggest that the improvement of response inhibition seen following methylphenidate administration is due to its influence on underlying attentional mechanisms linked to response control requirements.

Key Words: Attentional-capture, fMRI, methylphenidate, motor response inhibition, right inferior frontal gyrus, stop-signal task

M ethylphenidate, is the most frequently prescribed medication for attention-deficit/hyperactivity disorder (ADHD), improving symptoms of inattention, hyperactivity, and impulsiveness $(1,2)$. These symptoms have been attributed to a dysfunctional frontostriatal catecholaminergic system $(1,2)$. Methylphenidate is an indirect catecholamine agonist that blocks catecholamine transporters, thereby enhancing striatal dopamine levels, with catecholamine upregulation effects in extrastriatal brain regions $(3,4)$. Functional magnetic resonance imaging (fMRI) has shown that methylphenidate enhances cognitive functions by modulating frontostriatal activation in healthy and ADHD populations (5-12).

Methylphenidate has particularly beneficial effects on response inhibition (13-15), typically assessed with the stop-signal task (SST) (16), during which participants are required to inhibit a motor response to a "go" signal, if followed by an infrequent and unpredictable "stop" signal. Along with other regions (i.e., presupplementary motor area [SMA], subthalamic and caudate nucleus), the right inferior frontal gyrus (IFG) is considered a key area associated with inhibitory function (17-19).

A common confound of the SST, however, is that stop signals are, by necessity of the task design, infrequent and hence capture attentional resources. Furthermore, activation in the right IFG and striato-parieto-temporal regions has been associated with attention allocation to infrequent stimuli $(20-23)$, adults with ADHD show an abnormal magnetoencephalographic signature in the

From the Department of Neuroimaging (AMP, OGO, SCRW, MAM) and Department of Child and Adolescent Psychiatry (KR), Institute of Psychiatry, King's College London, United Kingdom; and Faculty of Psychology and Neuroscience (WJR), Maastricht University, The Netherlands.

Address correspondence to Astrid Pauls, M.Sc., Centre for Neuroimaging Sciences, Institute of Psychiatry, King's College London, De Crespigny Park, Box 089, SE5 8AF, London; E-mail: Astrid.Pauls@kcl.ac.uk. Received Aug 4, 2011; revised Mar 1, 2012; accepted Mar 14, 2012. ventral attentional system (24), and methylphenidate has been found to upregulate and normalize front-parietal activation during selective attention for infrequent stimuli in children with ADHD (25). The low frequency of stop signals is consequently a potential confound in understanding the underlying function of the pharmacologic modulation of the right IFG using SSTs (25-28).

This study is the first to attempt to understand the modulatory effects of methylphenidate on neural networks of motor response inhibition and error detection in healthy volunteers controlling for the attentional-capture effect. We used a traditional (18) and a modified SST that contained additional attentional-capturing trials, not significantly affecting the outcome measures typically assessed with the SST (28). We hypothesized that the effect of methylphenidate on right IFG activation would be associated with attentionalcapture, and would hence be observed during both successful inhibition and attentional capture trials. We also tested methylphenidate effects on successful inhibition after controlling for attentional capture. Additionally, in line with previous evidence for modulating effects of methylphenidate on performance monitoring $(29,30)$ and its underlying neural networks in ADHD patients (5), we expected methylphenidate to modulate performance-monitoring networks during failed inhibition.

\section{Methods and Materials}

\section{Participants}

Nineteen right-handed male adults were recruited via circulars within King's College London. Participants provided written informed consent, and the study was approved by the Joint South London and Maudsley/Institute of Psychiatry Research Ethics Committee (No. 08/H0807/105). Participants were reimbursed for their time and inconvenience. Participants underwent a screening procedure including a medical history, physical examination, hematology check, and a biochemistry blood and substance of abuse screen performed as a urine test (cocaine, cannabinoids, opiates, benzodiazepines, and amphetamines; SureScreen Diagnostics, Derby, United Kingdom). Exclusion criteria were 1) prior diagnosis of any psychiatric or neurologic disorder; 2) current prescription or nonprescription medication use; 3 ) previous ( $>5$ occasions) or current 
(within the past 3 months) illicit drug use; 4 ) alcohol intake of $>30$ units per week, use of nicotine-containing products ( $>5$ cigarettes per day), or caffeine ( $>6$ drinks per day); 5 ) a body mass index $>30$ $\mathrm{kg} / \mathrm{m}^{2}$ or total body weight $>100 \mathrm{~kg}$; and 6) magnetic resonance imaging (MRI) contraindications (e.g., metallic implants, claustrophobia).

Participants were screened for possible ADHD using the Adult ADHD Self-Report Scale (ASRS) Symptom Checklist with a cutoff score of 17 (out of 36) points for each subscale (31), except for one participant who scored 20 on subscale A. IQ was predicted using the National Adult Reading Test (NART) (32). Participants were native speakers or fluent in English. Three participants were not included in the data analysis because of inadequate task performance (i.e., $<40 \%$ or $>60 \%$ correctly inhibited trials). We replaced one participant after experiencing agitation and an increase in heart rate following drug administration. The final sample comprised 16 participants aged 19 to 30 (mean $\pm S D=23.6 \pm 3.6$ ); ASRS subscale A: $11.8 \pm 3.3$; ASRS subscale B: $10.4 \pm 2.9 ;$ NART full scale IQ $=118.3 \pm 4.8$.

\section{Design}

A double-blind, placebo-controlled, crossover design was used, comprising two scanning sessions. During a prior screening visit participants received instructions and training on the tasks and were familiarized with the scanner environment (Section S5 in Supplement 1). For each scanning visit, participants were required to abstain from alcohol; caffeine- (i.e., any drink containing caffeine such as coffee, tea, soft-drinks), grapefruit-, tobacco-, or nicotinecontaining products; any over-the-counter medication; and strenuous exercise from 24 hours before and after dosing. Scans were separated by at least 5 days to allow adequate washout of methylphenidate. During the first scanning session, participants received either a single oral dose of immediate-release methylphenidate (Ritalin, Novartis, Basel, Switzerland; $40 \mathrm{mg}$ ) or an ascorbic acid placebo $(50 \mathrm{mg}$ ) presented in identical capsules, counterbalanced for the second session. The methylphenidate dose was chosen to balance the known cognitive and side effects $(10,33)$.

\section{Procedure}

Peak plasma levels of methylphenidate are reached after 1 to 2 hours, and plasma half-life is 2 to 4 hours (34). To maximize methylphenidate effects, scanning commenced 1.5 hours after dosing (35). Visual analogue scales (VAS) were completed predose, 1 hour postdose (Sections S10 and S11 in Supplement 1), and before discharge to measure methylphenidate effects on subjective feelings (36).

\section{Stop-Signal Tasks}

Participants performed two versions of the SST both with an interstimulus interval of 1.65 seconds and comprising 220 trials. Participants had to respond to a go signal, an arrow pointing left or right (shown for 300 msec in the center of the field of view) with the corresponding hand, unless a stop signal (a red circle shown for 300 msec) followed indicating that participants had to inhibit their ongoing response. Both versions comprised 44 stop signals (i.e., $20 \%$ of all trials). The delay between the go and the stop signal (SSD) was initially $150 \mathrm{msec}$ and changed dynamically according to a tracking procedure (16) in increments or decrements of $50 \mathrm{msec}$ (range $50-900 \mathrm{msec}$ ) to maintain participants' performance at $50 \%$ successfully inhibited trials.

The original task (oSST) was similar to previously used eventrelated $\mathrm{fMRI}$ versions $(18,37,38)$. In the attentional-capture version of the task (cSST), an attention-capturing signal was added in form of a green circle that required the go response to continue (28) and comprised 44 trials (i.e., $20 \%$ of all trials), and the delay between go and attentional-capture trials varied according to the SSD. To make the stop and attentional-capture signals distinctive from one another, one appeared just above and one below the screen center, counterbalanced between participants. Responses were recorded with two sphygmomanometer inflation bulbs ("squeeze balls"), one placed in each hand. A response force greater or equal to $30 \%$ of the individual baseline response force, defined as the mean force exerted earlier in 20 choice reaction time trials, counted as response because this clearly delineated intended responses from nonresponses in pilot testing (Section S5 in Supplement 1). Paradigms were programmed using Visual Basic (VB.net; Microsoft, Redmond, Washington) implemented on a PC running Windows XP Professional (Microsoft).

\section{Data Acquisition}

MRI data were obtained using a 3T GE Signa HDx System (General Electric, Milwaukee, Wisconsin) with an eight-channel head coil. Stimulus images were projected on a screen, clearly visible through mirrors placed in front of participants' eyes. One hundred eighty-four T2*-weighted images were acquired for each task version using a gradient echo planar imaging sequence with repetition time/echo time $=2000 / 30 \mathrm{msec}$, flip angle $=75^{\circ}, 38$ slices (sequential, top-bottom), slice thickness $/$ gap $=3 / .3 \mathrm{~mm}$, in-plane resolution $=3.3 \mathrm{~mm}^{2}$, and field of view $21.1 \mathrm{~cm}$. A high-resolution gradient echo planar image was also obtained for accurate spatial normalization (repetition time/echo time $=3000 / 30 \mathrm{msec}$, flip angle $=90^{\circ}, 43$ slices, slice thickness $/$ gap $=3 / .3 \mathrm{~mm}$, and in-plane resolution of $1.875 \mathrm{~mm}^{2}$ ).

\section{Behavioral Data Analysis}

Mean reaction times and mean response forces were analyzed with repeated-measures analysis of variance using SPSS 15.0 for Windows (IBM SPSS Inc., Chicago, Illinois). The stop signal reaction time (SSRT) was estimated using the integration method: the mean SSD is subtracted from the $n$th reaction time (RT), where $n$ is determined by multiplying the number of RTs in the go RT distribution by the overall probability of a correct response [i.e., $p$ (respond|signal)] $(16,38)$.

\section{Neuroimaging Data Analysis}

Image preprocessing and whole-brain analysis were carried out using Statistical Parametric Mapping software developed by the Functional Imaging Laboratory, University College London, (SPM5, www.fil.ion.ucl.ac.uk/spm), running in Matlab 7.0.1 (MathWorks, Natick, Massachusetts), on a UNIX platform (Solaris, Redwood City, California). The data were slice-time corrected to account for interslice differences in blood oxygen level-dependent (BOLD) signal sampling and realigned to correct for subject movement. No subject had displacement values greater than $2 \mathrm{~mm}$ (translation) or $3.5^{\circ}$ (rotation; Section S9 in Supplement 1). The data were coregistered to a high-resolution echo planar image, which was then used to estimate the parameters for spatially normalizing the data into a standard anatomical space (Montreal Neurological Institute). The resulting normalized volume time series was spatially smoothed using a Gaussian kernel of 8-mm full width at half maximum. Data were analyzed within the framework of the general linear model. A single-subject (first-level) model was created for each session for each participant, including regressors encoding go trials (separately for left- and right-hand responses), successful and failed stop trials, and for the CSST attentional-capture trials as regressors of interest. Weighted linear contrasts were used to create maps of 
Table 1. Behavioral Results $(N=16)$

\begin{tabular}{|c|c|c|c|c|}
\hline \multirow[b]{2}{*}{ Reaction Times } & \multicolumn{2}{|c|}{ Original Version of the Task } & \multicolumn{2}{|c|}{ Continue Version of the Task } \\
\hline & Methylphenidate & Placebo & Methylphenidate & Placebo \\
\hline Stop-Signal Reaction Time & $240(40)$ & $245(53)$ & $224(66)$ & $263(70)$ \\
\hline Mean Correct Go Trials & $399(47)$ & $403(39)$ & $404(56)$ & $401(48)$ \\
\hline SD for Correct Go Trials & $58(25)$ & $69(24)$ & 53 (19) & $56(16)$ \\
\hline Mean Successful Continue Trials & NA & NA & $432(53)$ & $423(39)$ \\
\hline Mean Failed Stop Trials & $389(55)$ & $392(41)$ & $404(61)$ & $395(50)$ \\
\hline No. Failed Stop Trials & $22(2.1)$ & $22(2.1)$ & $22(3.4)$ & $23(3.5)$ \\
\hline No. Successful Stop Trials & $21(1.8)$ & $22(1.2)$ & $21(2.3)$ & $20(2.4)$ \\
\hline
\end{tabular}

Mean reaction times are given in milliseconds. Numbers in parentheses are standard deviations (SD) of the means. NA, not applicable.

activation for each session, which were used in a group (second level) analysis. Statistical significance was defined following correction across the whole brain for multiple comparisons $(p<.05)$ on the basis of cluster extent (voxel threshold $p<.001$ ). If no drug effects were shown at this threshold, the effects of the drug were also assessed using small volume correction limited to an anatomic mask including the bilateral IFG, defined a priori in the WFU Pickatlas (Wake Forest University, Winston-Salem, North Carolina). Statistical significance was defined at the voxel level $(p<.05)$ corrected for multiple comparisons. This region of interest analysis is based on the prediction that methylphenidate will modulate right IFG activation during inhibition $(17,18,39)$ and during attentional-capture trials (20-23). For regions showing a significant effect of methylphenidate on activation, correlations were performed between these activation clusters and performance changes. Data were extracted using MARSBAR (40), and regions were defined using spherical masks with a radius of $10 \mathrm{~mm}$ around the peak coordinates.

Unexpectedly, methylphenidate modulated different clusters within the IFG in a context-dependent manner (see Results). To test whether the differentially localized changes within the IFG reflect the recruitment of separate nodes within separate functional networks, we performed a seed-based functional connectivity analysis in an independent resting BOLD data set from 18 healthy volunteers (Section S7 in Supplement 1). For this analysis, SPM maps were thresholded at $p<.05$ after family wise error correction for multiple comparisons. Brodmann areas (BA) and brain regions were defined using the templates from MRIcron (www.cabiatl.com/mricro/ mricron).

\section{Results}

\section{Behavioral Results}

Mean performance values are reported in Table 1. The SSRT was shorter following methylphenidate compared with placebo administration for both tasks but reached significance only for the CSST $\left(t_{15}=-2.37, p=.03\right) ;$ oSST $\left(t_{15}=-.36, p=.72\right)$. This result supports previous findings in ADHD and healthy volunteers $(13,14)$. Methylphenidate did not significantly influence reaction times or accuracy ( $p s>.1)$. For the cSST, mean reaction time of successful attentionalcapture trials was, as expected (28), slower than mean reaction time to go trials $[F(1,15)=38.5, p<.001$; Section S8 in Supplement 1].

\section{Neuroimaging Results}

Methylphenidate Effects on Stop and Attentional-Capture Versus Go Trials. Successful stopping (SS $>$ Go) activated a network of brain regions consistent with the previous literature in both tasks (Section S1 in Supplement 1). The effects of methylphenidate are shown in Figure 1. Compared with placebo, methylphenidate reduced activation in the right IFG close to the anterior insula dur- ing successful stop versus go trials both on the oSST (BA 47; $x, y, z=$ $44,28,-2 ; 350$ voxels; $\left.Z=4.8 ; p_{\text {cor }}=.001\right)$ and the cSST (BA 47; $x, y$, $z=32,26,-14 ; 101$ voxels, $Z=4.05 ; p_{\text {cor }}=.04$; corrected for multiple comparisons within the bilateral IFG a priori-defined region of interest; Section S3 in Supplement 1).

To assess attentional-capturing effects in the cSST, we contrasted correct attentional-capture with go trials (Cont $>$ Go), which controlled for the motor response. We found a significantly decreased activation following methylphenidate administration compared with placebo in the right orbital inferior frontal cortex (orbIFG; BA 47; $\mathrm{x}, \mathrm{y}, \mathrm{z}=30,20,-22,41$ voxels; $Z=4.38 ; p_{\text {cor }}=.02$; correction for bilateral IFG).

In both tasks the failed stops contrast (Failed Stops $>$ Go trial; FS $>$ Go) identified brain regions previously associated with failed stopping (Section S1 in Supplement 1). Methylphenidate administration reduced $\mathrm{FS}>\mathrm{Go}$ activation compared with placebo in the right anterior insula cortex on the oSST (BA 48; $x, y, z=36,14,-4$, 404 voxels; $Z=4.47 ; p_{\text {cor }}=.002$ ) proximal to the region modulated during successful stopping. The same region also showed reduced activity for the CSST, although this was not statistically significant $(Z=2.62)$. Methylphenidate also significantly increased activation on the CSST in the left paracentral lobule when compared with placebo for failed stop versus go trials (BA $4 / 6 ; x, y, z=-16,-28,58$, 211 voxels; $Z=4.70 ; p_{\text {cor }}=.018$ ).

Methylphenidate effects for Successful and Failed Stop Trials Versus Attentional-Capture Trials. The CSST has the advantage that the attentional-capture trials themselves can be used as the control condition because, unlike the go trials, they are matched in frequency and temporal structure with the stop trials (28). Furthermore, the use by others of failed stop trials as a control condition has been questioned, because failed stop trials also activate inhibitory processes (41). Using the attentional-capture trials as control condition (SS > Cont), successful stop trials were not associated with any significant modulation of brain activation by methylphenidate compared to placebo in an analysis of variance model (Section S2 in Supplement 1). For failed stop versus attentional-capture trials (FS > Cont) methylphenidate significantly increased activation in seven clusters compared with placebo: the left medial frontal cortex, anterior cingulate cortex, bilateral angular gyrus, left postcentral gyrus, and left inferior occipital cortex; see Table 2, and Sections S1 and S4 in Supplement 1. The mean signal change per treatment condition is shown in Figure 2.

All drug effects remained significant when we controlled for order of drug administration.

Correlations with Performance. There were no statistically significant correlations between brain activations changes with methylphenidate and performance changes.

Functional Connectivity Analysis in an Independent Data 
A
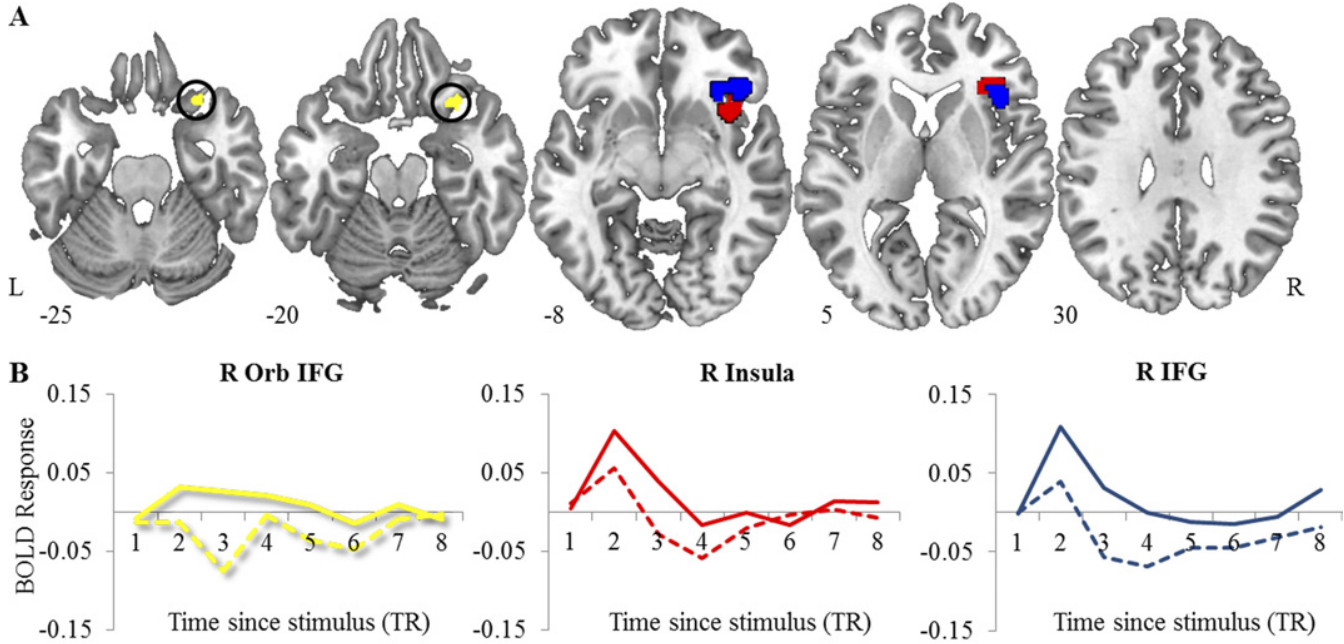

C
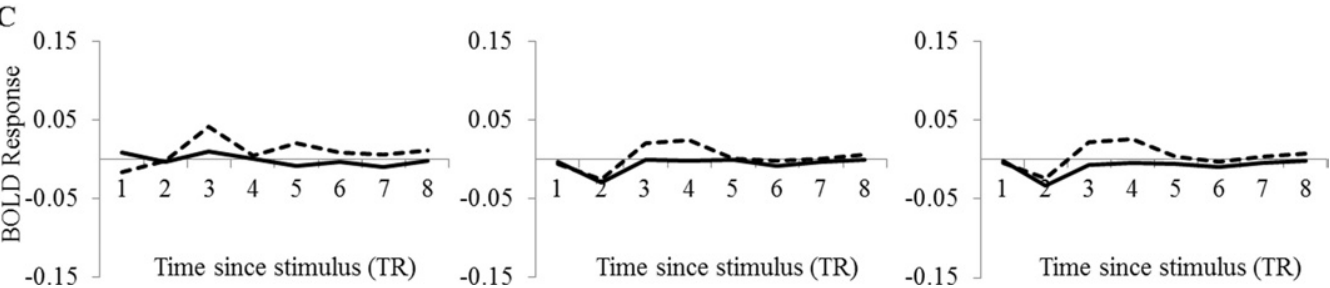

Figure 1. (A) The effects of methylphenidate on stop and attentional-capture versus go trials overlaid on a high resolution T1-weighted image in Montreal Neurological Institute space. Methylphenidate attenuated brain activation for the contrasts successful stop $>$ go in the right inferior frontal gyrus (R IFG, blue), failed stop $>$ go in the right insula/IFG (red) and continue $>$ go in the right orbital IFG (yellow). Clusters are corrected for multiple comparisons on the basis of cluster extent. Numbers refer to z coordinates. (B) The graphs show the peristimulus time histograms of the cluster peaks (sphere $=5 \mathrm{~mm}$; representing the average volume-to-volume change in blood oxygen level-dependent [BOLD] signal in response to the stimulus-type presented) for the right orbital IFG during successful continue trials, the right insula during failed stops, and the right IFG during successful stops. The colors correspond to those in panel A. The solid line shows the BOLD response for placebo, the dotted line shows the BOLD response for methylphenidate. Units for time since stimulus (TR) 2 sec. (C) The graphs show the peristimulus time histograms of the cluster peaks (for the R orbital [Orb] IFG, the R insula, and the R IFG) during go trials. The columns correspond to the columns in Panel A. The solid line shows the BOLD response for placebo, and the dotted line shows the BOLD response for methylphenidate. Unit for time since stimulus (TR) $=2$ seconds. L, left.

Group. Methylphenidate modulated brain activation in both stop and attentional-capture trials in the right IFG with the former located in the posterior medial IFG (pmIFG)/insula and the latter in the orbIFG. To determine whether these are functionally distinct regions, a seed-based functional connectivity analysis was carried out on independent resting state data. Because this functional connectivity analysis does not assess whether methylphenidate alters functional coupling, but the more fundamental question of whether the right pmIFG and orbIFG are functionally separable regions, it was preferable to analyze resting state data from an independent group of 18 healthy volunteers (Section S7 in Supplement 1$)$. Right pmIFG BOLD signal $(x, y, z=32,26,-14)$ was

Table 2. Failed Stop $>$ Continue $(N=16)$

\begin{tabular}{lrrrrrrl}
\hline & $\mathrm{x}$ & $\mathrm{y}$ & $\mathrm{z}$ & $\mathrm{BA}$ & Voxels & $\mathrm{Z}$ & Pcor \\
\hline Frontal Superior L & -14 & 54 & 22 & 32 & 406 & 5.29 & $<.005$ \\
Cingulum Anterior R & 16 & 46 & 6 & 32 & 325 & 4.16 & $<.005$ \\
Cingulum Anterior L & -4 & 22 & 20 & 24 & 205 & 4.08 & $<.05$ \\
Post Central L & -20 & -38 & 66 & 3 & 218 & 4.35 & $<.05$ \\
Angular L & -50 & -66 & 32 & 39 & 295 & 4.23 & $<.005$ \\
Angular R & 48 & -54 & 38 & 39 & 288 & 3.76 & $<.005$ \\
Occipital Inferior L & -48 & -58 & -14 & 37 & 444 & 4.04 & $<.001$
\end{tabular}

The effect of methylphenidate for the continue version of the task contrast failed stop $>$ continue. See also Section S4 in Supplement 1.

$B A, B r o d m a n n$ area; $L$, left; pcor, $p$ value corrected for multiple comparisons on the basis of cluster extent $R$, right. functionally coupled with an extensive network of regions including the inferior and medial frontal cortices, insula, anterior cingulate cortex, temporal cortex, SMA, pre-SMA, basal ganglia, and temporal and occipital, cortices (Figure 3). The right orbIFG signal $(x, y, z=30$, $20,-22)$ significantly correlated with overlapping areas mainly encompassing components of a ventral attentional system (41), including the inferior and medial frontal cortices, insula, temporal lobes, thalamus, and hippocampus. When the two connectivity maps were contrasted against each other, the right pmIFG connectivity pattern was significantly more extensive compared with the orbIFG connectivity pattern with differences in the cingulate cortex, SMA/pre-SMA, insula and amygdala, and superior, medial, and orbital frontal cortices (Figure 3).

\section{Discussion}

The main findings of this study are that a single dose of methylphenidate improved inhibitory performance and concomitantly reduced activation within distinct regions of the right IFG/insula in response to successful and failed inhibition as well as attentional capture. Methylphenidate increased activation within the medial frontal and the anterior cingulate, on error trials, but not successful inhibition when controlling for attentional capture. This suggests upregulation of neural systems of attention allocation to errors by methylphenidate different from the modulatory effects on inhibition and attentional-capture trials. 


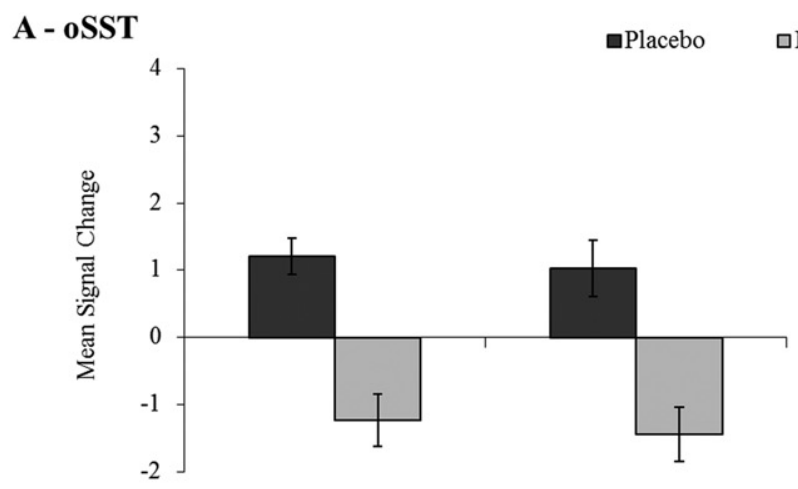

Successful Stop $>$ Go R IFG Failed Stop $>$ Go R Insula

\section{B - cSST}

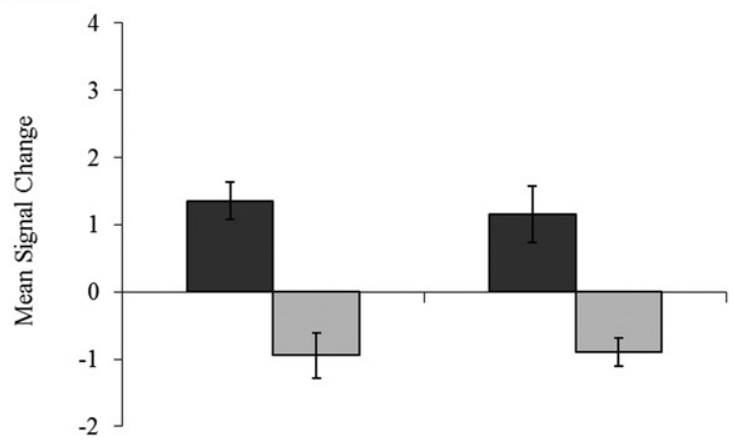

Successful Stop $>$ Go R IFG Continue $>$ Go R orb IFG

\section{C - cSST}

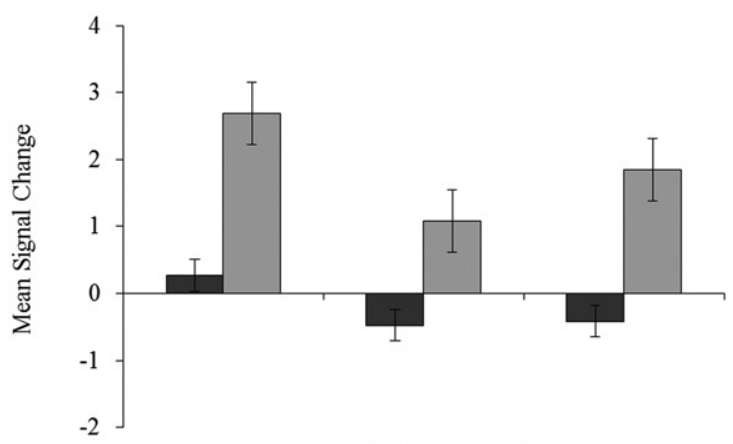

Failed Stop $>$ Continue

L ACC R ACC L Sup Front

Figure 2. The significant mean signal changes (i.e., model fit statistic for a specific contrast) per treatment condition. Mean values were extracted from the clusters of interest of each contrast. (A) Original version of the task (oSST); right (R) inferior frontal gyrus (IFG; successful stop $>$ go) and R insula (failed stop $>$ go). (B) Continue version of the task (cSST); R inferior frontal gyrus (successful stop $>$ go) and R orbital (orb) IFG (continue $>$ go). (C) Left (L)/R anterior cingulate cortex (ACC) and L superior frontal cortex (Sup Front; failed stop $>$ continue). Error bars indicate the standard error of mean. MPH, methylphenidate.

\section{Methylphenidate Effects on Stop and Attentional-Capture Trials}

Methylphenidate, relative to placebo, modulated distinct parts of the right IFG/insula when we contrasted successful stop, failed stop, or attentional-capture trials against go trials. It is possible that this reduction reflects a generalized response to low-frequency stopping cues, with subtle variations within the medial prefrontal structures depending on whether they were successfully or unsuccessfully inhibited. During successful stops, pmIFG activity was reduced by methylphenidate, which overlapped closely with the reduced activity on failed stops (centered in the anterior insula cortex). Further studies are required to determine whether these two effects are dissociable. During attentional-capture trials, methylphenidate reduced activation in a more orbital part of the right IFG. It is conceivable that attentional-capture trials may have evoked some degree of inhibitory control, albeit less than stop trials (43), slowing down the reaction time of participants. Attentionalcapturing stimuli in the absence of inhibitory requirements typically have a slowing effect on reaction time, even if they are not task relevant $(44,45)$, and in a study conducted by Sharp et al. (28), response slowing was associated with activation within the preSMA but not the IFG. In line with these findings, we have found that response slowing on attentional-capture trials did not explain the effects in the IFG (Section S6 in Supplement 1). The IFG downregulation under methylphenidate was no longer observed when stop trials were contrasted with attentional-capture trials. Exploring potential modulatory effects, we found an indication of an increased activation in a small, nonsignificant cluster (six voxels) in the orbIFG following methylphenidate (Section S2 in Supplement 1). This may reflect restricted statistical power for the contrast, although using a similar number of trials, the failed stop versus attentional-capture comparison showed significant differences in activation. We therefore propose that the reduction of activation in the right IFG following methylphenidate during successful inhibition may be due to context-dependent effects on underlying neurofunctional attention systems associated with the presentation of infrequent stimuli signaling altered response control, which help to improve inhibition performance. The right IFG has been found to be involved in the processing of infrequent stimuli and suggested to be part of a ventral attentional system $(21,27,28,42,46)$. However, we should be cautious about drawing firm conclusions without further investigation in larger samples.

Our data suggest that the modulation of attentional-capture by methylphenidate is context-dependent because of the modulation of different IFG locations. Methylphenidate-related reduction in attentional-capture activity in the orbital IFG likely reflects modulated processing of an unexpected, but behaviorally irrelevant cue in the context of a response inhibition paradigm (28). The connectivity of this orbIFG region with a network encompassing elements of the ventral attentional system (42) further supports the notion that methylphenidate modulates shifts of attention to unexpected/ low-frequency stimuli. Confirmation of this role requires a task that manipulates the frequency of unexpected stimuli. In contrast, the pmIFG region, that was downregulated by methylphenidate during the successful stop trials was functionally interconnected with more superior brain regions, including the anterior cingulate and SMA/pre-SMA, as well as basal ganglia areas. These regions are key components of inhibitory networks (17-19), suggesting that methylphenidate modulated networks that mediate shifts of attention to low-frequency stimuli that require altered action. Thus, an account of methylphenidate's effects on IFG function may require consideration of both attentional processing and response control. The presence of distinct regions modulated during attentionalcapture trials and stop trials further suggests a fractionation of IFG function that may be related to catecholaminergic innervations.

Research in experimental animals has shown that prefrontal dopamine D1 and alpha-2 noradrenergic receptors may underpin the effects of methylphenidate and that the balance of dopamine D1 and D2 receptor stimulation is important for the signal-to-noise 


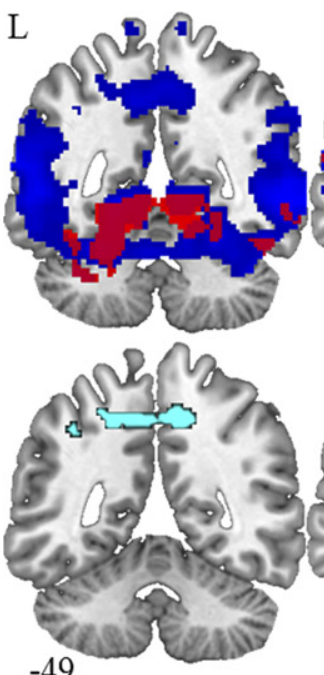

$-49$
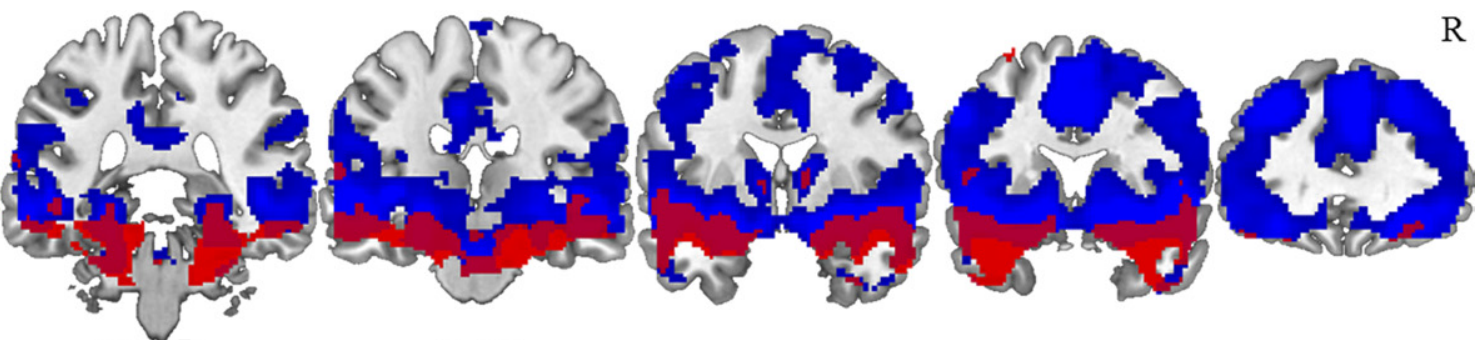

$\mathrm{R}$
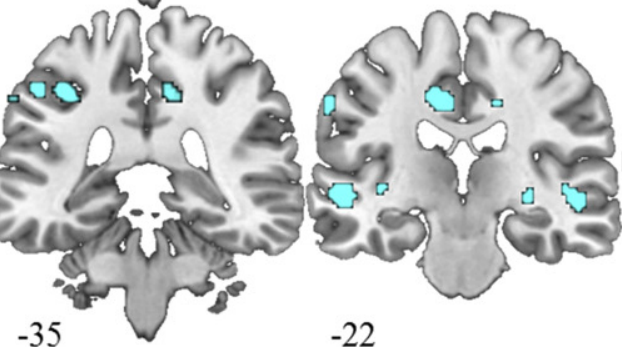

$-22$

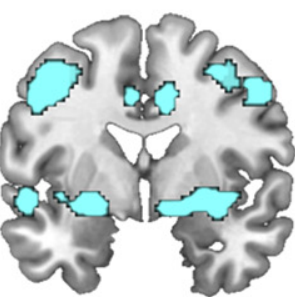

$-1$

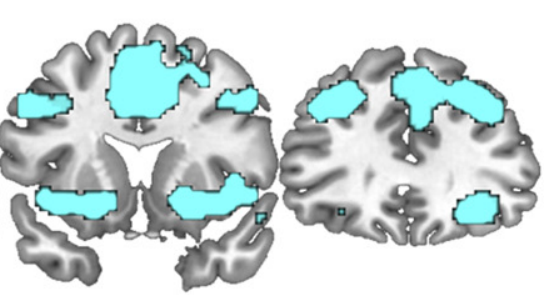

13
33

Figure 3. Significant correlations in an independent (nondrug) group between the right (R) posterior medial inferior frontal gyrus (blue) and the right orbital inferior frontal gyrus (red) with other brain regions overlaid on a high resolution T1-weighted image in Montreal Neurological Institute space (upper panel). All correlations were positive. The lower panel shows the difference between the two connectivity maps (right posterior medial inferior frontal gyrus $>$ orbital right inferior frontal gyrus). Slices refer to the y coordinates of the Montreal Neurological Institute standard anatomical space. Clusters are corrected for multiple comparisons on the basis of cluster extent: $p<.05$. L, left.

ratio of prefrontal activity (47). This leads to the prediction that methylphenidate may be fine-tuning prefrontal activity in line with the inverted- $U$ hypotheses. However, the relationship between these receptor effects shown in animals and brain activity in humans is poorly elucidated. We can speculate that the reductions in prefrontal activity relate to an altered balance of signal-to-noise ratio mediated by dopamine and noradrenaline receptors and that this translates to reductions in $\mathrm{fMRI}$ signal. The reduction is consistent with a previous positron emission tomography study in healthy volunteers in which the same dose of methylphenidate reduced activity in dorsolateral prefrontal cortex accompanied by improved working memory performance (10).

In contrast, in two recent studies, response inhibition was associated with the upregulation of IFG activity following atomoxetine administration $(39,48)$. In one study atomoxetine was associated with an impaired inhibitory performance (48), and in the other, inhibitory performance improved (39). This conflicting effect may be explained by differences in doses ( 80 versus $40 \mathrm{mg}$, respectively). Nevertheless, the differential effects on activation of methylphenidate and atomoxetine suggest opposite effects on right IFG activity, potentially attributable to the different pharmacologic mechanisms (49). Performance on both tasks in this study was numerically better on methylphenidate but significantly only on one version. Although differences in performance have previously been found to affect fMRI findings (50), in our study methylphenidate consistently decreased right IFG activation during successful inhibition across both tasks. Further work is needed to determine more precisely the mechanisms through which these BOLD signal changes relate to neuronal activity.

\section{Methylphenidate Effects on Failed Stop Versus Attentional- Capture Trials}

During failed stop versus attentional-capture trials, methylphenidate relative to placebo elicited increased BOLD signal in a number of regions. These included the dorsomedial frontal cortex, comprising BAs 8,6 , and 32, including pre-SMA and anterior cingulate, a typical region involved in error processing and performancemonitoring in adults (51-53). The BOLD responses in these regions reflected clear increases in event-related activity (Section S4 in Supplement 1). Also upregulated was the parietal cortex, associated with visual attention (54) and attention modulation (55), although the BOLD response did not clearly follow the typical hemodynamic time course, and this finding should be interpreted with caution. No effect of methylphenidate on post-error slowing was found. Increased inhibitory errors following atomoxetine has previously been associated with increased activation of the bilateral IFG and pre-SMA (48). However, given the link of the modulated regions with processing failed inhibition and error detection (18,38,51$53,56)$ and the notion that phasic dopamine response modulates error-related mesial frontal activation (57), we speculate that methylphenidate enhances attention allocation to trial errors $(51,58)$, presumably leading to a more conscious processing of errors $(29,30,59,60)$. Importantly, this effect was only detected when controlling for attentional capture.

\section{Relevance to ADHD}

Although there have been some findings of decreases of activation with methylphenidate, the majority of studies in ADHD patients found that methylphenidate enhanced or normalized brain activation that is typically underactivated in patients $(5,61)$. These findings are largely in line with the upregulation of medial frontal areas in this study during failed inhibitions and suggest that upregulation of performance-monitoring networks may be a shared mechanism of action of methylphenidate in healthy adults and ADHD patients.

However, during successful inhibition and attention functions, methylphenidate appears to have a differential effect of IFG downregulation in healthy adults and IFG upregulation in ADHD patients, likely because of different baseline dopamine levels, age, gender effects, or differences in task design. Nevertheless, our findings in healthy subjects have implications for the mechanisms of action of methylphenidate in ADHD patients, suggesting that the IFG modulation observed in ADHD during inhibition $(5,9,11,62)$ may be due to effects on underlying attention mechanisms linked to response control. 


\section{Conclusion}

Overall, this study showed clear modulation of the right IFG by methylphenidate in healthy adults during two SST tasks, although the precise regions modulated differed for inhibition, attentionalcapture, and error trials. Specifically, methylphenidate modulated a more posterior region of the IFG functionally connected with cortical and subcortical regions associated with motor control during infrequent stimuli signaling the requirement for inhibition. During infrequent but behaviorally irrelevant stimuli, methylphenidate modulated an orbital region of the IFG, functionally connected with cortical areas associated with the ventral attention system (63). When we controlled for the attentional-capture effect, methylphenidate also modulated performance-monitoring networks during failed inhibition. Our findings show that methylphenidate effects on response inhibition are likely due to its influence on attentional mechanisms linked to action.

We thank Stephanie Stephenson for assistance during data collection, Jeff Dalton and Christopher Andrew for development of the task, Dr. Fernando Zelaya for advice on the scanning protocol and Dr. Ellen Migo for advice on the manuscript.

$M A M$ and $A M P$ designed the research; $A M P$ and OGO performed the research; $A M P, O G O$, and $M A M$ analyzed the data; and $A M P, O G O, K$. Rubia, WJR, SCRW, and MAM wrote the article.

$A M P$ and $O G O$ reported no biomedical financial interests or potential conflicts of interest. MAM receives research funding from Eli Lilly and is a scientific advisor to Cambridge Cognition. KR has received funding from Eli Lilly for another research project and speakers honoraria from Eli Lilly, Shire, and Medice. During the study, WJR was employed by Hoffman-LaRoche R\&D, Basel, Switzerland, while remaining affiliated to Maastricht University. SCRW receives research funding from Pfizer, Eli Lilly, and Takeda.

The data were published in form of posters at the following conferences: Pauls AM, O'Daly OG, Mehta MA (2010): Methylphenidate (MPH) effects on response inhibition networks: The role of attentional capture. Presented at the 16th Annual Meeting of the Organization for Human Brain Mapping; Barcelona, Spain; June 6-10, 2010. Pauls AM, O'Daly OG, Mehta MA (2010): Distinct effects of methylphenidate in the prefrontal cortex associated with attentional capture and response inhibition. Presented at the British Association for Psychopharmacology 2010 Summer Meeting, Harrogate, United Kingdom; July 25-28, 2010.

\section{Supplementary material cited in this article is available online.}

1. Arnsten AFT (2006): Stimulants: Therapeutic actions in ADHD. Neuropsychopharmacology 31:2376-2383.

2. Wilens TE (2008): Effects of methylphenidate on the catecholaminergic system in attention-deficit/hyperactivity disorder. J Clin Psychopharmacol 28(3 Suppl 2):S46-S53.

3. Krause J (2008): SPECT and PET of the dopamine transporter in attention-deficit/hyperactivity disorder. Expert Rev Neurother 8:611-625.

4. Hannestad J, Gallezot JD, Planeta-Wilson B, Lin SF, Williams WA, van Dyck $\mathrm{CH}$, et al. (2010): Clinically relevant doses of methylphenidate significantly occupy norepinephrine transporters in humans in vivo. Biol Psychiatry 68:854-860.

5. Rubia K, Halari R, Mohammad AM, Taylor E, Brammer M (2011): Methylphenidate normalizes frontocingulate underactivation during error processing in attention-deficit/hyperactivity disorder. Biol Psychiatry 70 : 255-262.

6. Dodds CM, Muller U, Clark L, van Loon A, Cools R, Robbins TW (2008): Methylphenidate has differential effects on blood oxygenation leveldependent signal related to cognitive subprocesses of reversal learning. J Neurosci 28:5976-5982.
7. Mehta MA, Goodyer IA, Sahakian BJ (2004): Methylphenidate improves working memory and set-shifting in AD/HD: Relationships to baseline memory capacity. J Child Psychol Psychiatry 45:293-305.

8. Rubia K, Halari R, Christakou A, Taylor E (2009): Impulsiveness as a timing disturbance: Neurocognitive abnormalities in attention-deficit hyperactivity disorder during temporal processes and normalization with methylphenidate. Phil Trans Royal Soc B Biol Sci 364:1919-1931.

9. Vaidya CJ, Austin G, Kirkorian G, Ridlehuber HW, Desmond JE, Glover GH, et al. (1998): Selective effects of methylphenidate in attention deficit hyperactivity disorder: A functional magnetic resonance study. Proc Natl Acad Sci U S A 95:1494-1499.

10. Mehta MA, Owen AM, Sahakian BJ, Mavaddat N, Pickard JD, Robbins TW (2000): Methylphenidate enhances working memory by modulating discrete frontal and parietal lobe regions in the human brain. $J$ Neurosci 20:RC65.

11. Rubia K, Halari R, Cubillo A, Smith AB, Mohammad AM, Brammer M, et al. (2011): Methylphenidate normalizes fronto-striatal underactivation during interference inhibition in medication-naive boys with attentiondeficit hyperactivity disorder. Neuropsychopharmacology 36:15751586.

12. Marquand AF, De Simoni S, O'Daly OG, Williams SCR, Mourao-Miranda J, Mehta MA. (2011): Pattern classification of working memory networks reveals differential effects of methylphenidate, atomoxetine, and placebo in healthy volunteers. Neuropsychopharmacology 36:1237-1247.

13. Aron AR, Dowson JH, Sahakian BJ, Robbins TW (2003): Methylphenidate improves response inhibition in adults with attention-deficit/hyperactivity disorder. Biol Psychiatry 54:1465-1468.

14. Nandam LS, Hester R, Wagner J, Cummins TDR, Garner K, Dean AJ, et al. (2011): Methylphenidate but not atomoxetine or citalopram modulates inhibitory control and response time variability. Biol Psychiatry 69:902904.

15. Overtoom CCE, Bekker EM, van der Molen MW, Verbaten MN, Kooij JJS, Buitelaar JK, et al. (2009): Methylphenidate restores link between stopsignal sensory impact and successful stopping in adults with attentiondeficit/hyperactivity disorder. Biol Psychiatry 65:614-619.

16. Verbruggen F, Logan GD (2009): Models of response inhibition in the stop-signal and stop-change paradigms. Neurosci Biobehav Rev 33:647661.

17. Aron AR, Robbins TW, Poldrack RA (2004): Inhibition and the right inferior frontal cortex. Trends Cogn Sci 8:170-177.

18. Rubia K, Smith AB, Brammer MJ, Taylor E (2003): Right inferior prefrontal cortex mediates response inhibition while mesial prefrontal cortex is responsible for error detection. Neurolmage 20:351-358.

19. Aron AR, Behrens TE, Smith S, Frank MJ, Poldrack RA (2007): Triangulating a cognitive control network using diffusion-weighted magnetic resonance imaging (MRI) and functional MRI. J Neurosci 27:3743-3752.

20. Downar J, Crawley AP, Mikulis DJ, Davis KD (2001): The effect of task relevance on the cortical response to changes in visual and auditory stimuli: An event-related fMRI study. Neuroimage 14:1256-1267.

21. Rubia K, Hyde Z, Halari R, Giampietro V, Smith A (2010): Effects of age and sex on developmental neural networks of visual-spatial attention allocation. Neuroimage 51:817-827.

22. Downar J, Crawley AP, Mikulis DJ, Davis KD (2002): A cortical network sensitive to stimulus salience in a neutral behavioral context across multiple sensory modalities. J Neurophysiol 87:615-620.

23. Kirino E, Belger A, Goldman-Rakic P, and McCarthy G (2000): Prefrontal activation evoked by infrequent target and novel stimuli in a visual target detection task: An event-related functional magnetic resonance imaging study. J Neurosci 20:6612-6618.

24. Helenius P, Laasonen M, Hokkanen L, Paetau R, Niemivirta M (2011): Impaired engagement of the ventral attentional pathway in ADHD. Neuropsychologia 49:1889-1896.

25. Rubia K, Halari R, Cubillo A, Mohammad AM, Brammer M, Taylor E (2009): Methylphenidate normalises activation and functional connectivity deficits in attention and motivation networks in medication-naive children with ADHD during a rewarded continuous performance task. Neuropharmacology 57:640-652.

26. Chikazoe J, Jimura K, Asari T, Yamashita Kl, Morimoto H, Hirose S, et al. (2009): Functional dissociation in right inferior frontal cortex during performance of Go/No-Go task. Cereb Cortex 19:146-152.

27. Hampshire A, Chamberlain SR, Monti MM, Duncan J, Owen AM (2010): The role of the right inferior frontal gyrus: Inhibition and attentional control. Neuroimage 50:1313-1319. 
28. Sharp DJ, Bonnelle V, De Boissezon X, Beckmann CF, James SG, Patel MC, et al. (2010): Distinct frontal systems for response inhibition, attentional capture, and error processing. Proc Natl Acad Sci 107:6106-6111.

29. Groen Y, Mulder LJM, Wijers AA, Minderaa RB, Althaus M (2009): Methylphenidate improves diminished error and feedback sensitivity in ADHD: An evoked heart rate analysis. Biol Psychol 82:45-53.

30. Jonkman LM, van Melis JJM, Kemner C, Markus CR (2007): Methylphenidate improves deficient error evaluation in children with ADHD: An event-related brain potential study. Biol Psychol 76:217-229.

31. Kessler RC, Adler L, Ames M, Demler O, Faraone S, Hiripi EVA, et al. (2005): The World Health Organization adult ADHD self-report scale (ASRS): A short screening scale for use in the general population. Psychol Med 35:245-256.

32. Nelson HE, Willison JR (1991): The Revised National Adult Reading Test-Test Manual. Windsor, United Kingdom: NFER-Nelson.

33. Bullmore E, Suckling J, Zelaya F, Long C, Honey G, Reed L, et al. (2003): Practice and difficulty evoke anatomically and pharmacologically dissociable brain activation dynamics. Cereb Cortex 13:144-154.

34. Gualtieri CT, Wargin W, Kanoy R, Patrick K, Shen CD, Youngblood W, et al. (1982): Clinical studies of methylphenidate serum levels in children and adults. J Am Acad Child Adolesc Psychiatry 21:19-26.

35. Faraj BA, Israili AH, Perel JM, Jenkins ML, Holtzman SG, Cucinell SA, et al. (1974): Metabolism and diposition of methylphenidate -14C: Studies in man and animals. J Pharmacol Exp Ther 191:535-547.

36. Bond A, Lader M (1974): The use of analogue scales in rating subjective feelings. Br J Med Psychol 47:211-218.

37. Rubia K, Smith AB, Brammer MJ, Toone B, Taylor E (2005): Abnormal brain activation during inhibition and error detection in medicationnaive adolescents with ADHD. Am J Psychiatry 162:1067-1075.

38. Rubia K, Smith AB, Taylor E, Brammer M (2007): Linear age-correlated functional development of right inferior fronto-striato-cerebellar networks during response inhibition and anterior cingulate during errorrelated processes. Hum Brain Mapp 28:1 163-1177.

39. Chamberlain SR, Hampshire A, Mueller U, Rubia K, del Campo N, Craig K et al. (2009): Atomoxetine modulates right inferior frontal activation during inhibitory control: A pharmacological functional magnetic resonance imaging study. Biol Psychiatry 65:550-555.

40. Brett M, Anton J-L, Valabregue R, Poline J-B (2002): Region of interest analysis using an SPM toolbox [abstract]. Paper presented at: 8th International Conference on Functional Mapping of the Human Brain; June 2-6, 2002; Sendai, Japan. Available on CD-ROM in Neuroimage Vol 16, No 2

41. Boehler CN, Appelbaum LG, Krebs RM, Hopf JM, Woldorff MG (2010): Pinning down response inhibition in the brain-conjunction analyses of the stop-signal task. Neuroimage 52:1621-1632.

42. Corbetta M, Kincade JM, Shulman GL (2002): Neural systems for visual orienting and their relationships to spatial working memory. J Cogn Neurosci 14:508-523.

43. van Gaal S, Ridderinkhof KR, van den Wildenberg WPM, Lamme VAF (2009): Dissociating consciousness from inhibitory control: Evidence for unconsciously triggered response inhibition in the stop-signal task. $J$ Exp Psychol Hum Percept Perform 35:1129-1139.

44. Dalton P, Lavie N (2004): Auditory attentional capture: effects of singleton distractor sounds. J Exp Psychol Hum Percept Perform 30:180-193.

45. Mason DJ, Humphreys GW, Kent L (2004): Visual search, singleton capture, and the control of attentional set in ADHD. Cogn Neuropsychol 21:661-687.
46. Huettel SA, McCarthy G (2004): What is odd in the oddball task?: Prefrontal cortex is activated by dynamic changes in response strategy. Neuropsychologia 42:379-386.

47. Seeman P, Madras B (2002): Methylphenidate elevates resting dopamine which lowers the impulse-triggered release of dopamine: A hypothesis. Behav Brain Res 130:79-83.

48. Graf H, Abler B, Freudenmann R, Beschoner P, Schaeffeler E, Spitzer M, et al. (2011): Neural correlates of error monitoring modulated by atomoxetine in healthy volunteers. Biol Psychiatry 69:890-897.

49. Bymaster FP, Katner JS, Nelson DL, Hemrick-Luecke SK, Threlkeld PG, Heiligenstein $\mathrm{JH}$, et al. (2002): Atomoxetine increases extracellular levels of norepinephrine and dopamine in prefrontal cortex of rat: a potential mechanism for efficacy in attention deficit/hyperactivity disorder. Neuropsychopharmacology 27:699-711.

50. Schlaggar BL, Brown T, Lugar HM, Visscher KM, Miezin FM, Petersen SE (2002): Functional neuroanatomical differences between adults and school-age children in the processing of single words. Science 296: $1476-1479$.

51. Bekker EM, Kenemans JL, Hoeksma MR, Talsma D, Verbaten MN (2005): The pure electrophysiology of stopping. Int J Psychophysiol 55:191-198.

52. Ramautar JR, Slagter HA, Kok A, Ridderinkhof KR (2006): Probability effects in the stop-signal paradigm: The insula and the significance of failed inhibition. Brain Res 1105:143-154.

53. Ridderinkhof KR, Ullsperger M, Crone EA, Nieuwenhuis S (2004): The role of the medial frontal cortex in cognitive control. Science 306:443-447.

54. De Fockert J, Rees G, Frith C, Lavie N (2004): Neural correlates of attentional capture in visual search. J Cogn Neurosci 16:751-759.

55. Hayden BY, Nair AC, McCoy AN, Platt ML (2008): Posterior cingulate cortex mediates outcome-contingent allocation of behavior. Neuron 60:19-25.

56. Pliszka SR, Glahn DC, Semrud-Clikeman M, Franklin C, Perez R III, Xiong J, et al. (2006): Neuroimaging of inhibitory control areas in children with attention deficit hyperactivity disorder who were treatment naive or in long-term treatment. Am J Psychiatry 163:1052-1060.

57. Holroyd CB, Baker TE, Kerns KA, Müller U (2008): Electrophysiological evidence of atypical motivation and reward processing in children with attention-deficit hyperactivity disorder. Neuropsychologia 46:22342242.

58. Alderson RM, Rapport MD, Sarver DE, Kofler MJ (2008): ADHD and behavioral inhibition: A re-examination of the stop-signal task. J Abnorm Child Psychol 36:989-998.

59. Krusch DA, Klorman R, Brumaghim JT, Fitzpatrick PA, Borgstedt AD, Strauss J (1996): Methylphenidate slows reactions of children with attention deficit disorder during and after an error. J Abnorm Child Psychol 24:633-650.

60. Hester R, Nandam LS, O'Connell RG, Wagner J, Strudwick M, Nathan PJ. et al (2012): Neurochemical enhancement of conscious error awareness. J Neurosci 32:2619-2627.

61. Paloyelis $Y$, Mehta MA, Kuntsi J, Asherson P (2007): Functional MRI in ADHD: A systematic literature review. Expert Rev Neurother 7:13371356.

62. Bush G, Spencer TJ, Holmes J, Shin LM, Valera EM, Seidman LJ, et al. (2008): Functional magnetic resonance imaging of methylphenidate and placebo in attention-deficit/hyperactivity disorder during the multi-source interference task. Arch Gen Psychiatry 65:102-114.

63. Corbetta M, Shulman GL (2002): Control of goal-directed and stimulusdriven attention in the brain. Nat Rev Neurosci 3:201-215. 